\title{
Lung Cancer Screening: Evidence, Risks, and Opportunities for Implementation
}

\section{Lungenkrebs-Screening: Evidenz, Risiken und Möglichkeiten der Implementierung}

Authors

Giulia Tringali ${ }^{1}$, Gianluca Milanese ${ }^{1}$, Roberta Eufrasia Ledda ${ }^{1}$, Ugo Pastorino ${ }^{2}$, Nicola Sverzellati ${ }^{1}$, Mario Silva ${ }^{1}$

Affiliations

1 Department of Medicine and Surgery (DiMeC Scienze Radiologiche), University of Parma, Italy

2 Department of Thoracic Surgery, Fondazione IRCCS Istituto Nazionale dei Tumori, Milano, Italy

Key words

pulmonary nodule, lung cancer, guidelines, lungRADS, screening

received 25.11 .2020

accepted 19.01.2021

published online 26.03.2021

Bibliography

Fortschr Röntgenstr 2021; 193: 1153-1161

DOI $10.1055 / \mathrm{a}-1382-8648$

ISSN 1438-9029

(C) 2021. Thieme. All rights reserved.

Georg Thieme Verlag KG, Rüdigerstraße 14,

70469 Stuttgart, Germany

Correspondence

Dr. Mario Silva

Section "Scienze Radiologiche", Department of Medicine and Surgery (DiMeC), University of Parma, Pad. Barbieri, via Gramsci 14, 43121 Parma, Italy

Tel.: +39/3475271936

mario.silva@unipr.it

\section{ZUSAMMENFASSUNG}

Hintergrund Lungenkrebs ist weltweit die häufigste zum Tode führende Krebserkrankung. Mehrere Studien mit unterschiedlichen Screening-Ansätzen haben die Rolle des Screenings mit Niedrigdosis-CT zur Reduzierung der LungenkrebsMortalität erkannt. Die Effektivität des Lungenkrebs-Screenings hängt von vielen Faktoren ab und dessen Implementierung steht in den meisten europäischen Ländern noch aus. Methoden Ziel dieser Übersicht ist die Darstellung der aktuellen Evidenz des Lungenkrebs-Screenings mit Schwerpunkt auf den möglichen Chancen für Implementierungsstrategien. Die Säulen der Lungenkrebs-Vorsorge werden anhand der aktuellsten Literatur diskutiert (PubMed-Suche bis 16. November 2020).
Ergebnisse und Schlussfolgerungen Die NELSON-Studie zeigte eine Reduktion der Lungenkrebs-Mortalität und bestätigte damit frühere Ergebnisse unabhängiger europäischer Studien, insbesondere hinsichtlich des Volumens der LungenRundherde. Die Heterogenität bei der Patientenrekrutierung könnte die Effektivität des Screenings beeinflussen, daher sind Risikomodelle und Community-basiertes Screening von Bedeutung. Die Rekrutierungsstrategien werden kontinuierlich weiterentwickelt und angepasst, um den spezifischen Bedürfnissen der heterogenen Population potenzieller Teilnehmer gerecht zu werden. Die aktuellsten Erkenntnisse hierzu stammen aus Großbritannien. Das Lungenkrebs-Screening der Zukunft besteht aus einem maßgeschneiderten Ansatz mit personalisierter, kontinuierlicher Risikostratifizierung, das darauf abzielt, Kosten und Risiken zu reduzieren.

\section{Kernaussagen:}

- Die Sekundärprävention von Lungenkrebs durch Niedrigdosis-Computertomografie zeigte eine Reduktion der Lungenkrebs-Mortalität.

- Die semi-automatische Volumenmessung sowie der Einsatz der Volumenverdopplungszeit sollten die Referenzmethode zur Risikooptimierung sein, nämlich die Kontrolle der Messvariabilität und der falsch-positiven Rate.

- Ein konservativer Ansatz mit Überwachung von subsoliden Rundherden kann eine der Strategien sein, um das Risiko einer Überdiagnose und Überbehandlung zu reduzieren.

- Ziel eines maßgeschneiderten Ansatzes mit personalisierter Risikostratifizierung ist die Reduzierung von Kosten und Risiken. Ein längeres Intervall zwischen den Visiten ist eine Option für Teilnehmer mit geringerem Risiko.

\section{ABSTRACT}

Background Lung cancer is the most common cause of cancer death worldwide. Several trials with different screening approaches have recognized the role of lung cancer screening with low-dose CT for reducing lung cancer mortality. The efficacy of lung cancer screening depends on many factors and implementation is still pending in most European countries. Methods This review aims to portray current evidence on lung cancer screening with a focus on the potential for opportunities for implementation strategies. Pillars of lung cancer 
screening practice will be discussed according to the most updated literature (PubMed search until November 16, 2020). Results and Conclusion The NELSON trial showed reduction of lung cancer mortality, thus confirming previous results of independent European studies, notably by volume of lung nodules. Heterogeneity in patient recruitment could influence screening efficacy, hence the importance of risk models and community-based screening. Recruitment strategies develop and adapt continuously to address the specific needs of the heterogeneous population of potential participants, the most updated evidence comes from the UK. The future of lung cancer screening is a tailored approach with personalized continuous stratification of risk, aimed at reducing costs and risks.

\section{Key Points:}

- Secondary prevention of lung cancer by low-dose computed tomography showed a reduction of lung cancer mortality.
- Semi-automated volume measurement and use of volume doubling time should be the reference method for optimization of risks, namely controlling measurement variability and the false-positive rate.

- A conservative approach with surveillance of subsolid nodules can be one of the strategies to reduce the risk of overdiagnosis and overtreatment.

- The goal of a tailored approach with personalized risk stratification aims to reduce costs and risks. A longer interval between rounds is one option for participants at lower risk.

\section{Citation Format}

- Tringali G, Milanese G, Ledda RE et al. Lung Cancer Screening: Evidence, Risks, and Opportunities for Implementation. Fortschr Röntgenstr 2021; 193: 1153-1161

\section{Introduction}

Lung cancer (LC) is one of the leading causes of death worldwide. Accounting for more than $20 \%$ of cancer deaths in Europe, it ranks first among oncological diseases [1]. Cigarette smoking is the major risk factor for the development of LC, and programs aiming at smoking cessation represent the most important intervention for primary prevention of LC mortality [2]. Furthermore, strategies for LC mortality reduction include early detection by low-dose computed tomography (LDCT), namely lung cancer screening (LCS). Throughout the last two decades, more than 100000 subjects were enrolled in different LCS trials to explore the impact of selection criteria, screening design, and screening interval [3-10].

Notably, the first positive results were reported in 2011 by the National Lung Screening Trial (NLST), the largest randomized LCS trial organized in the US testing annual LDCT against annual chest radiography (CXR), with a $20 \%$ reduction in LC mortality by LDCT [8]. This observation prompted the US Preventive Services Task Force (USPSTF) to recommend annual LDCT screening for asymptomatic adults aged 55 to 80 years with a cumulative tobacco exposure of at least 30 pack years and current smokers (or former smokers, quitting within the past 15 years) [11]. After NLST, the results of European LCS trials followed [3-7]. In 2020, the largest European trial, the Dutch-Belgian LCS trial (NederlandsLeuvens Longkanker Screenings Onderzoek, NELSON, more than 15000 subjects enrolled) [9], confirmed over $20 \%$ LC mortality by LDCT. Secondary observations followed, both from NELSON and other European trials, including the use of volumetry and volume doubling time (VDT) [9], a conservative approach to slow-growing neoplasms $[12,13]$, the cumulative effect of prolonged LCS [5, 14], high efficacy in the female population [9, 10], and the possibility of a biennial interval between screening rounds $[15,16]$.

Based on these positive results, scientific societies and healthcare systems are working to implement LCS at the population level. The transition from trial "exercise" to population "routine" has encountered several criticisms, including economic sustainability
[17]. A number of post hoc cost-effectiveness analyses showed that LCS could be cost-effective, albeit with a strict relationship with selection criteria, screening algorithm (i. e., number and timing of LDCT rounds, based on LDCT outcome), and the implementation of supportive measures, first of all smoking cessation programs $[17,18]$. The latter is particularly effective not only for the purposes of LC but also mainly for reducing the impact of other diseases (e. g., cardiovascular diseases, non-oncological pulmonary diseases) [19]. The contribution of integrated smoking cessation in LCS is expected to magnify the reduction in overall mortality [20], indeed cardiovascular diseases (CVD) are the leading cause of death in smokers. This was demonstrated in the NLST alongside a proposal for CVD risk stratification by simple visual assessment of coronary artery calcium (CAC) in ungated LDCT [21, 22]. This article will be reviewing the most recent literature about LCS and its multifaceted workflow ( $\triangleright$ Fig. 1).

\section{Selection criteria, patient recruitment, and risk stratification}

LCS trials initiated in the 2000 s used selection criteria based on age and smoking history ( $>$ Table 1 ). This approach seems convenient due to its simplicity. However, further factors are involved in the stratification of LC risk, including family history and chronic obstructive pulmonary disease (COPD). Examples of comprehensive risk models factoring multidimensional risk factors into a continuous scale were developed and these showed improvement of screening efficacy ( $\triangleright$ Table 2 ). In 2013, the PLCOm2012 model showed higher sensitivity than NLST criteria alone in predicting LC risk in six years (threshold $\geq 1.51$ ) [23]. Furthermore, results from the Pan-Canadian Early Detection of Lung Cancer (PanCan) study showed that the PanCan risk model (a precursor of PLCOm2012; threshold $\geq 2 \%$ LC risk in 6 years) was effective in identifying subjects at high risk for LC [24]. First in Europe, the UK Lung Cancer Screening Trial (UKLS) adopted the Liverpool Lung Project version 2 (LLPV2) risk model (threshold $\geq 5 \%$ LC risk 


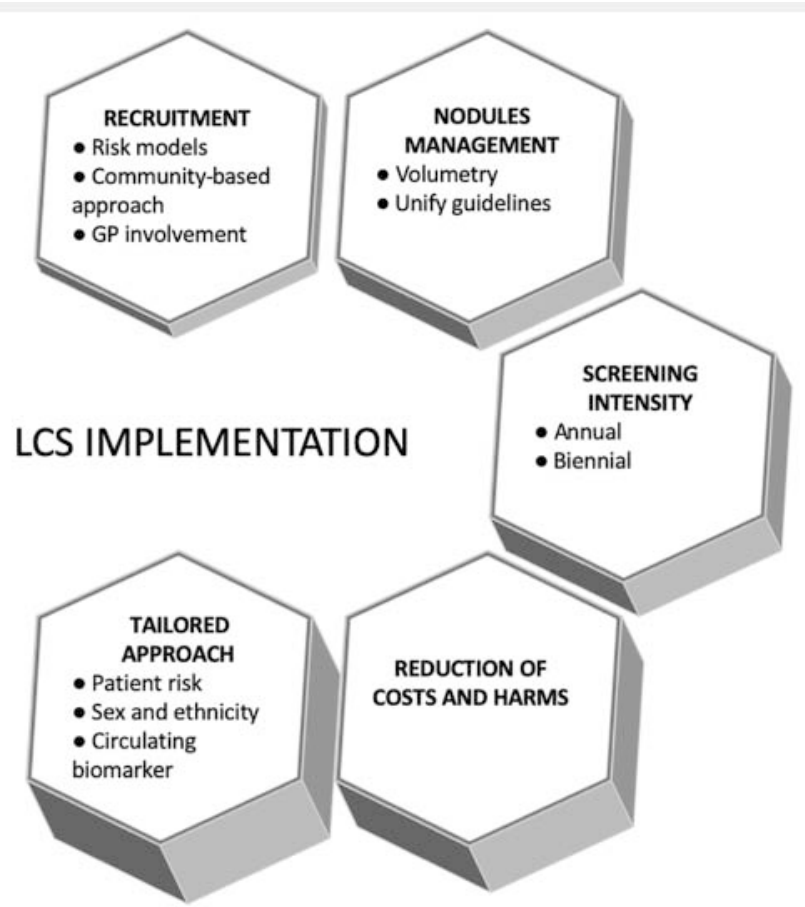

- Fig. 1 Infographics showing the hierarchical approach to lung cancer screening practice and its continuous quality assurance and development.

- Abb. 1 Hierarchischer Ansatz des Lungenkrebs-Screenings in der Praxis mit ständiger Qualitätskontrolle und Weiterentwicklung.

in 5 years), which includes asbestos exposure, family history of LC at an early age, previous malignancies, and non-oncological respiratory diseases [3]. The PanCan and the UKLS showed a $5.4 \%$ and $1.7 \%$ prevalence of $L C$ at baseline, respectively. It is noteworthy that such a prevalence is higher than that reported by the NELSON and the NLST, which both showed close to $1 \%$ prevalence of LC at baseline [3, 24]. An analysis of the performance of four risk models (PLCOm2012, LLPv2, LCRAT, Bach) using data from the German federal-wide survey and LC incidence data in the German population suggests a good calibration in the comparison between predicted versus observed LC incidence for the PLCOm2012 model, whereas the LLPV2 model tends to overestimate risk and to select older subjects [25]. To overcome such limitations, the LLPv2 risk model was recently updated to LLPv3 using current cancer incidence data from England and adding age standardization, showing a better performance in absolute lung cancer risk prediction (threshold of $2.5 \%$ risk of LC in 5 years), and it is recommended for future LCS trials in the UK [26].

Selection of higher risk populations, beyond age and cumulative tobacco exposure, is a cornerstone of LCS performance and, thus, should be valued to optimize the efficacy and sustainability of LCS at the population level. Nonetheless, the use of these models comes with the potential drawback of its complexity, which is relatively higher compared to the simple threshold of age and pack years. Of note, the NELSON selection criteria could be
- Table 1 Summary of the selection criteria based on age and smoking history used by the major lung cancer screening trials.

- Tab.1 Zusammenfassung der Auswahlkriterien der wichtigsten Lungenkrebs-Screening-Studien hinsichtlich des Alters und der Raucheranamnese.

\begin{tabular}{|c|c|c|}
\hline $\begin{array}{l}\text { lung cancer } \\
\text { screening trial }\end{array}$ & selection criteria: smoking history & $\begin{array}{l}\text { selection } \\
\text { criteria: } \\
\text { age }\end{array}$ \\
\hline NELSON [9] & $\begin{array}{l}\text { - } 15 \text { cigarettes/day for }>25 \text { years } \\
\text { - }>10 \text { cigarette/day for }>30 \text { years } \\
\text { - current or former smokers who quit } \\
\text { smoking } \leq 10 \text { years ago }\end{array}$ & $50-75$ \\
\hline NLST [8] & $\begin{array}{l}\text { " at least } 30 \text { pack years } \\
\text { - current or former smokers who quit } \\
\leq 15 \text { years ago }\end{array}$ & $55-74$ \\
\hline MILD [5] & - at least 20 pack years & $49-75$ \\
\hline UKLS [3] & - risk stratification by LLP v2 model & $50-75$ \\
\hline LUSI [10] & $\begin{array}{l}\text { - } 15 \text { cigarettes/day for }>25 \text { years } \\
\text { - }>10 \text { cigarettes/day for }>30 \text { years } \\
\text { - current or former smokers who quit } \\
\text { smoking } \leq 10 \text { years ago }\end{array}$ & $50-69$ \\
\hline ITALUNG [7] & $\begin{array}{l}\text { - at least } 20 \text { pack years in the last } \\
10 \text { years }\end{array}$ & $55-69$ \\
\hline DANTE [4] & $\begin{array}{l}\text { - at least } 20 \text { pack years } \\
\text { - quit smoking }<10 \text { years }\end{array}$ & $60-74$ \\
\hline DLCST [6] & $\begin{array}{l}\text { - at least } 20 \text { pack years } \\
\text { - quit smoking < } 10 \text { years }\end{array}$ & $50-70$ \\
\hline
\end{tabular}

- Table 2 Summary of the major comprehensive risk models adopted by lung cancer screening trials.

- Tab. 2 Zusammenfassung der wichtigsten umfassenden Risikomodelle, die bei Lungenkrebs-Screening-Studien angewandt wurden.

\begin{tabular}{|c|c|c|}
\hline $\mathrm{PLCO}_{\mathrm{m} 2012}[22]$ & $\begin{array}{l}\text { PanCan model } \\
\text { [23] }\end{array}$ & $\operatorname{LLP}_{\mathrm{v} 2}[24]$ \\
\hline $\begin{array}{l}\text { - age } \\
\text { - education } \\
\text { - family history } \\
\text { of lung cancer } \\
\text { - body mass } \\
\text { index } \\
\text { - COPD } \\
\text { - smoking } \\
\text { duration } \\
\text { - smoking } \\
\text { intensity } \\
\text { - smoking quit } \\
\text { time } \\
\text { - personal } \\
\text { history of } \\
\text { cancer } \\
\text { - race or ethnic } \\
\text { origin }\end{array}$ & $\begin{array}{l}\text { - age } \\
\text { - education } \\
\text { - family history of } \\
\text { lung cancer } \\
\text { - body mass index } \\
\text { - chest X-ray in } \\
\text { last } 3 \text { years } \\
\text { - COPD history } \\
\text { - smoking history } \\
\text { (duration and } \\
\text { pack years) }\end{array}$ & $\begin{array}{l}\text { - age } \\
\text { - sex } \\
\text { - family history of lung } \\
\text { cancer } \\
\text { - personal history of } \\
\text { cancer } \\
\text { - personal history of } \\
\text { pneumonia or tubercu- } \\
\text { losis } \\
\text { - asbestos exposure } \\
\text { - cOPD, emphysema, } \\
\text { bronchitis } \\
\text { - smoking duration } \\
\text { - smoking intensity } \\
\text { - type of cigarette } \\
\text { smoked } \\
\text { - age at smoking start and } \\
\text { end }\end{array}$ \\
\hline
\end{tabular}


deemed already as a first step towards continuous scale models, because the NELSON protocol used two thresholds of smoking duration to convene a minimum threshold of risk.

Recruiting high-risk subjects has been difficult throughout the various LCS trials, in particular for the inclusion of disadvantaged socioeconomic groups, which are less likely to respond to a screening invitation [27]. The European Society of Radiology (ESR) and the European Respiratory Society (ERS) in their joint statement underlined the importance of reaching individuals with a low level of literacy [17], for whom both tailored communication and a collaborative process with healthcare providers were advocated by the American Thoracic Society (ATS) including Medicaid coverage [28]. Adherence to LCS is still variable even in the US where population screening has been proposed (and covered) for 5 years or more [29]. Recently, a cross-sectional study from the population-based Cancer Screening Program in Urban China (CanSPUC) showed a participation rate as low as $40 \%$ among more than 55000 high-risk participants, resulting in a potential weakening of LCS effectiveness. Several factors were associated with the lower participation rate, including age range 70-74 years, male gender, lower education level, no family history of LC, and current smoking status. Furthermore, the participation rate was heterogeneous between different regions, which can be related to a longer distance to the screening site [30]. To overcome such a limitation, the Manchester Lung Health Check program (a pilot community-based study) used mobile CT scanners placed outside shopping centers, with the purpose of providing access to LCS for high-risk subjects from the most deprived areas of Manchester [31]. Yet, the Western London trial recently showed that the screening participants did not prefer a mobile site over a fixed site, especially if the fixed site is located within an efficient commutation network [32]. Therefore, the optimal format of LCS should be specifically designed according to the target region. The German Lung Cancer Screening Intervention (LUSI) trial demonstrated a higher LC mortality reduction among women, a result also confirmed by the NELSON and NLST $[9,10]$. This is an important observation since women may show a higher adherence to LCS, allegedly related to their decennial experience with breast cancer screening. The above-mentioned CanSPUC study showed $50 \%$ adherence among women, compared to a significantly lower rate of $33 \%$ among men [30].

The refinement of individual risk stratification could be improved by circulating biomarkers (e.g., micro-RNA, cell-free DNA, exosomes, etc.), which are being tested in combination with LDCT results for the purpose of personalized LCS screening. Notably, a prospective 3-year follow-up was proposed after baseline of the bioMILD trial, in the case of a baseline solid nodule $<113 \mathrm{~mm}^{3}$ (or no nodule) and a low-risk biological profile by micro-RNA signature [33]. Further approaches include a PCR-based blood test to detect LC hypermethylation changes (Lung EpiCheck), which was recently validated in European and Chinese samples, with both high sensitivity and correlation with tumor size and aggressiveness [34]. The measurement of autoantibodies specific for tumor associated antigens was proposed in Scotland to tailor LDCT every 6 months, in a trial with > 12000 high-risk subjects [35].

\section{LDCT reading and reporting}

Reading and reporting LDCT in LCS is a relatively simple yet overwhelming practice that is quite prone to human error [36]. Computer-Aided Detection (CAD) is an important tool supporting radiologists with respect to the reading of LDCTs. In fact, CAD increases nodule detection, guarantees homogeneous measurements with minimum interobserver variability, and helps reduce reading time, thus minimizing false-negative results due to human distraction and fatigue [37]. Reading time was shorter when CAD was used as a concurrent reader (132 s) compared with LDCT reading being performed separately (first by radiologists and then with CAD: 210 s) [38]. CAD systems have been proven to outperform radiologists as the second reader. Nevertheless reading by radiologists with CAD assistance remains the most accurate approach due to the higher sensitivity compared to a combination of two CAD systems [39]. Complementarity of visual detection and CAD assistance was reported for subsolid nodules (SSN), the density of which might be suboptimal for automatic segmentation [40]. Along with CAD, (semi)automated software for nodule volume segmentation could be available and helps the consistency of measurement across reporting radiologists. However, pitfalls of semi-automated volumetry are acknowledged in the measurement of solid nodules abutting solid structures ( $\triangleright$ Fig. 2), subsolid nodules ( $\triangleright$ Fig. 3 ), and variability across different software packages (including evolving versions of the same software) [41]. Hwang et al. evaluated the degree of variability in CAD LDCT interpretation among radiologists from different institutions in the Korean Lung Cancer Screening project (K-LUCAS) by comparing with a retrospective central review, showing a higher inter-institution variability in LDCT reading caused by different use of CAD systems [42].

The first scan in the series of pluriannual LCS - the baseline - is the major source of nodule detection (nodule prevalence varying $10-70 \%$ depending on the reading method and size threshold), whereas from the second scan on - incidence rounds - the detection rate of new nodules is below $10 \%$ (any size). At baseline, the stratification of LDCT outcome (i. e., negative, indeterminate, and positive) relies on size threshold, which affects the number of LDCT scans to be performed after baseline. The size of a pulmonary nodule is the main factor driving the management of individuals undergoing LDCT evaluation, similarly in the LCS program and in daily clinical practice. Both the ESR/ERS statement and the British Thoracic Society (BTS) Guidelines recommend the use of semi-automated volumetric measurement for defining LDCT outcome, and the implementation of volume-doubling time (VDT) at LDCT follow-up [43]. The volumetric reference was developed in the NELSON trial and currently validated in the European Position Statement (EuPS), which will be largely applied in the next European trials and implementation in the population [44]. In brief, this approach includes both volume and longitudinal characterization of solid nodules by volume doubling time (VDT, thresholds at 400 and 600 days) [9]. VDT is an adjunct parameter for the reduction of the false-positive and overdiagnosis rate [9]. The North American experience was mainly based on diameter measurement, with NLST resulting in a false-positive rate (FP) as high as $96.4 \%$ in the LDCT arm and thus a positive predictive value as 


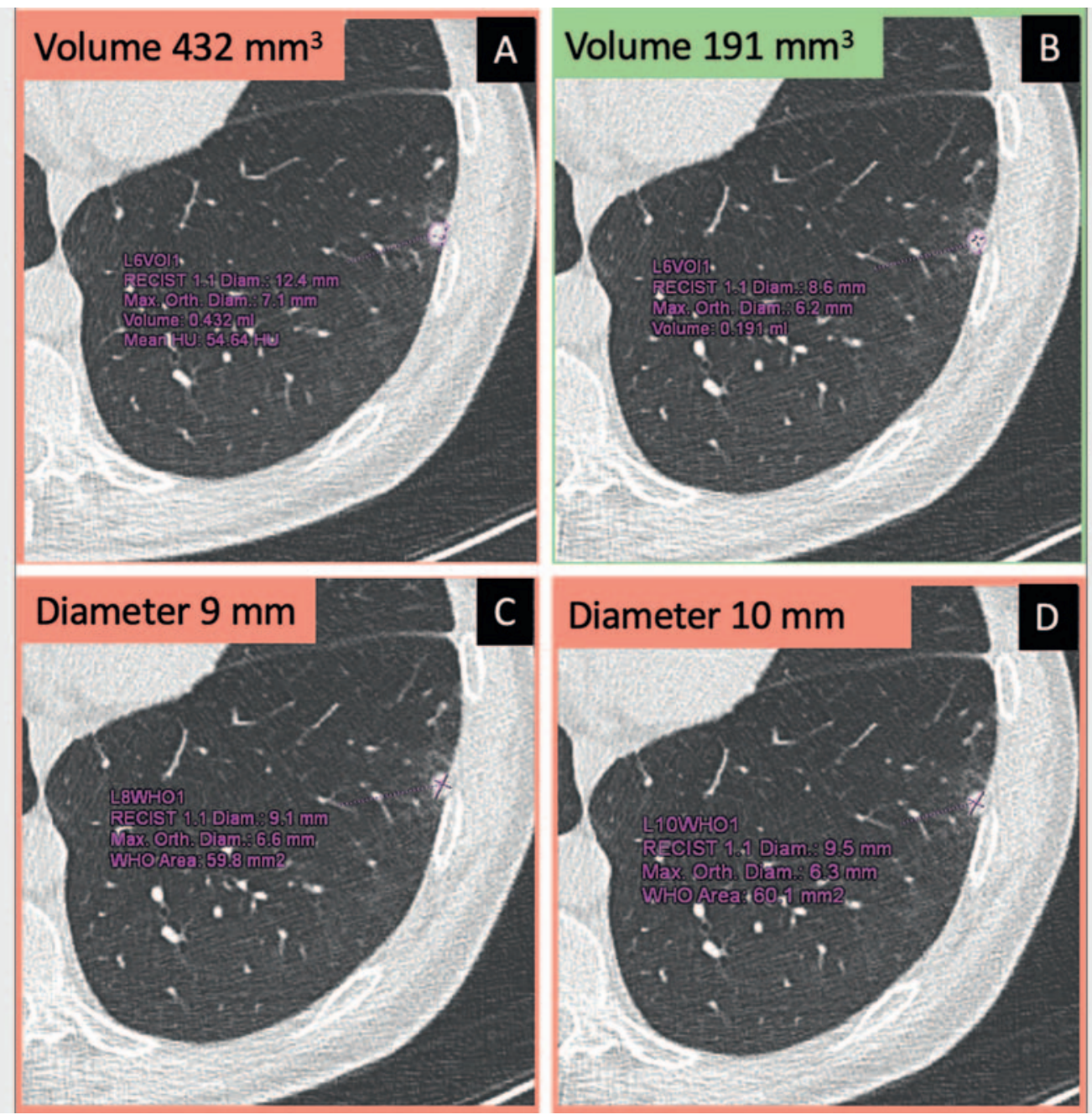

- Fig. 2 Solid nodule abutting solid structure: Comparison of nodule measurement variability by either semi-automatic segmentation of volume or manual caliper. Solid nodule abutting the pleural surface in the left lower lobe is measured twice with semi-automatic segmentation software with substantially different volume resulting in either 3-month follow-up (A: volume $432 \mathrm{~mm}^{3}$ ) or annual follow-up (B: volume $191 \mathrm{~mm}^{3}$ ). The same nodule is also measured twice by manual caliper with consistent classification and management with 3-month follow-up (C: diameter 9 mm; D: diameter $10 \mathrm{~mm})$. Reference method: BTS Guidelines.

- Abb.2 Solider Rundherd angrenzend an eine solide Struktur: Vergleich der Variabilität der Rundherdmessung entweder mit semi-automatischer Volumensegmentierung oder mit manuellem Caliper. Ein an die Pleuraoberfläche angrenzender solider Rundherd im linken Unterlappen wird zweimal mit einer semi-automatischen Segmentierungssoftware gemessen, wobei sich das Volumen erheblich unterscheidet, was entweder zu einer Nachuntersuchung nach 3 Monaten (A: Volumen 432 mm³ $^{3}$ oder nach einem Jahr (B: Volumen 191 mm $^{3}$ ) führt. Derselbe Rundherd wird auch zweimal mit einem manuellen Caliper gemessen, mit konsistenter Klassifizierung und einer Nachuntersuchung nach 3 Monaten (C: Durchmesser 9 mm; D: Durchmesser $10 \mathrm{~mm}$ ). Referenzmethode: BTS-Leitlinien.

low as $3.6 \%$ [8]. A retrospective analysis of the NLST data showed an optimized diameter threshold that was issued in the American College of Radiologists (ACR) Lung CT Screening Reporting \& Data System (Lung-RADS) in 2014, with a substantial reduction of the FP rate at baseline, at the cost of negligibly lower sensitivity [45]. In 2019, the ACR adapted its diameter classification to volumetric references, known as the Lung-RADS ${ }_{\mathrm{v} 1.1}$, by converting previous nodule diameter thresholds into volume. The interobserver agreement for Lung-RADS categorization by semi-automated volumetric measurement was higher than the categorization by diameter [46]. In brief, Lung-RADS ${ }_{\mathrm{v} 1.1}$ modified the diagnostic categories with downgrading of specific category 3 nodules (6-month fol- low-up) to category 2 (annual follow-up) [47]. Perifissural nodules with smooth margins $<524 \mathrm{~mm}^{3}(<10 \mathrm{~mm})$ are in category 2 of Lung-RADS ${ }_{\mathrm{v1.1}}$, in keeping with the former NELSON results: no LC at one-year follow-up was found originating from such nodules. Although the ACR committee did not consider nodules attached to the costal pleural in this update, recent results showed that nodules attached to the costal pleura $<10 \mathrm{~mm}$ identified at baseline with smooth margins and lentiform, oval, or triangular shape are benign. Therefore, the authors suggest a one-year follow-up rather than immediate workup [48]. Moreover, category 2 of Lung-RADS $_{\mathrm{v} 1.1}$ is also deemed for non-solid nodules (NSN, otherwise ground-glass GGN) $<14137 \mathrm{~mm}^{3}(<30 \mathrm{~mm})$. For these no- 

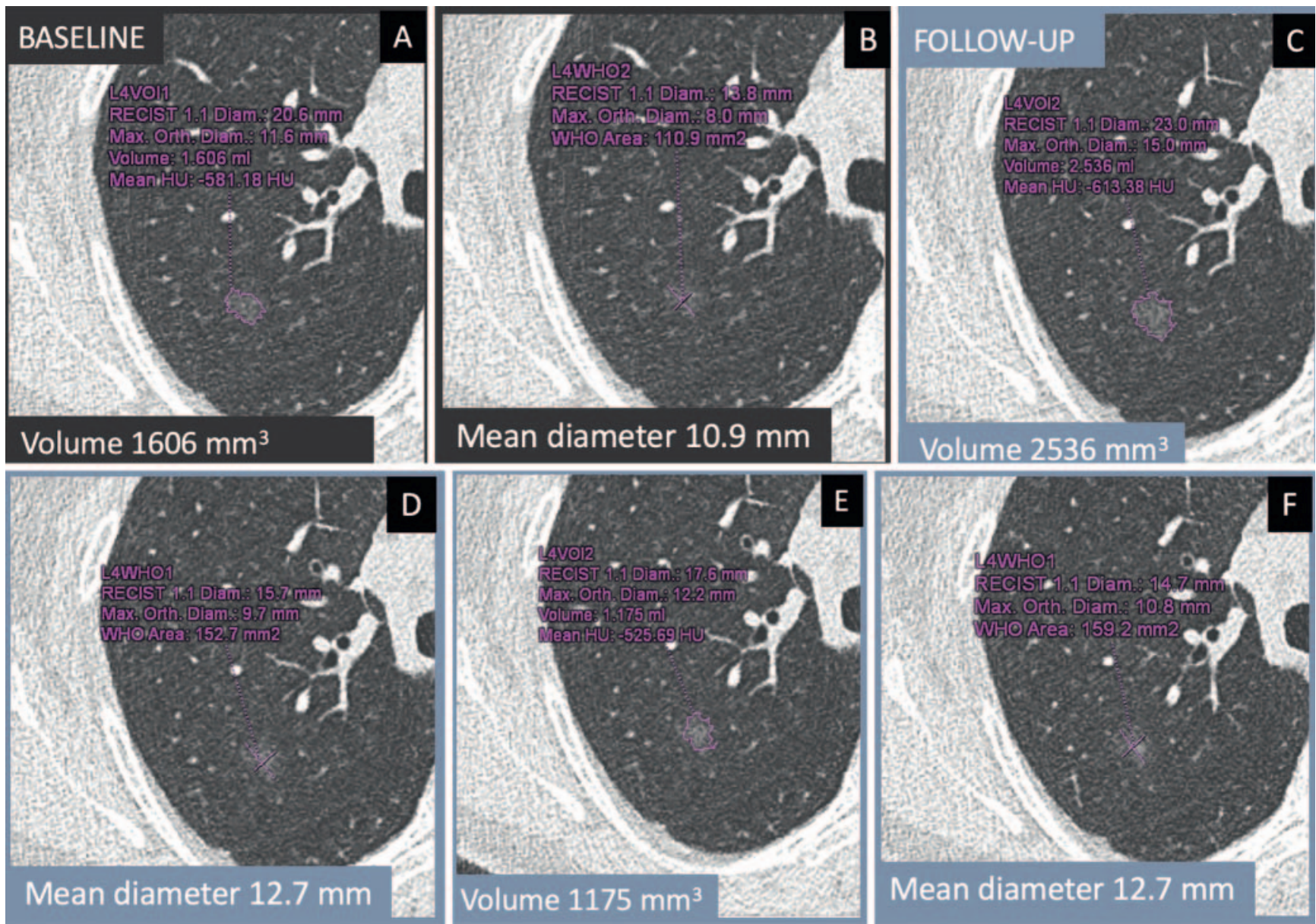

- Fig. 3 Subsolid nodule: Comparison of nodule measurement variability by either semi-automatic segmentation of volume or manual caliper for longitudinal characterization of non-solid nodule at follow-up low-dose CT. Non-solid nodule in the right upper lobe is measured at baseline with semi-automatic segmentation software (A: volume $1606 \mathrm{~mm}^{3}$ ) and by manual caliper (B: mean diameter $\left.10.9 \mathrm{~mm}\right)$. At follow-up, the same nodule is measured twice with semi-automatic segmentation software resulting in substantially different volumes (C: volume $2536 \mathrm{~mm}^{3} ; \mathbf{E}: 1175 \mathrm{~mm}^{3}$ ) and twice by manual caliper with moderate variability in individual diameters albeit a comparable mean diameter (D, F: mean diameter 12.7 mm).

- Abb. 3 Subsolider Rundherd: Größenunterschied in der Längscharakterisierung des nicht-soliden Rundherdes bei Verwendung von halbautomatischen Volumensegmentierung oder von Messchieber während der Nachkontrolle mit Low-Dose CT. Nicht-solider Rundherd in der rechten Oberlappe wird an Baseline mit halbautomatischen Volumensegmentierungsoftware (A: Größe $1606 \mathrm{~mm}^{3}$ ) oder mit Messschieder gemessen (B: Mittelwert Durchmesser $10.9 \mathrm{~mm}$ ). Die Messung mit halbautomatischen Volumensegmentierung desselber Rundherd wird während der Nachkontrolle zweimal ausgeführt und ergibt wesentlich unterschiedliche Werte (C: Größe $2536 \mathrm{~mm}^{3}$; E: $1175 \mathrm{~mm}^{3}$ ). Die zweimalige Messung mit Messchieber hingegen zeigt mäßige Schwankungen der individuellen Werte dennoch vergleichbarern Durchesser (D, F: Durchmesser 12,7 mm).

dules, 12-month follow-up can be considered safe given their indolent behavior, until progression or development of a solid component [13].

Other factors can influence FP results, including emphysema, COPD, and granulomatous processes (either infectious or idiopathic) [49]. Reading should be in the hands of trained and certified radiologists to both avoid false-negative results and reduce false-positive results, with the aim of minimizing unnecessary LDCT and interventions. The ESR/ERS document emphasizes the importance of radiologist expertise in LCS CTs reading, and a certification program by the European Society of Thoracic Imaging (ESTI) is available to train radiologists for LCS [17]. Radiologists should have read at least 200 chest CT scan/year. However, a greater experience and number of LDCT scans read/year might be preferred to achieve excellent clinical practice.

\section{Potential risks of lung cancer screening}

Overdiagnosis, namely the detection of a tumor that otherwise would not become clinically manifest, is a major issue of screening programs, including LCS. Overdiagnosis may lead to workup and treatment with consequent costs, risks, and potential reduction of quality of life (e. g. psychological impact) [50]. Overdiagnosis is quantified as the excess $\mathrm{LC}$ incidence in the screening arm as compared to the control arm ( $18.5 \%$ in the NLST and $19.7 \%$ in the NELSON) [8, 9]. Results from the LUSI demonstrated a $24.5 \%$ excess incidence at the 5.7-year follow-up, with a larger excess incidence of adenocarcinomas among women [51]. Nonetheless, the longer the follow-up period after screening, the lower the rate of overdiagnosis. Both NLST and NELSON reported data at 11 years, showing $1 \%$ in the NLST and $8.9 \%$ in the NELSON [9, 
14]. The Multicentric Italian Lung Detection (MILD) trial reported active surveillance of SSN until growth of a solid component as a safe strategy to reduce overdiagnosis/overtreatment [13]. This conservative approach is only one of the potential strategies to reduce the risks of LCS.

Beyond pulmonary nodules, other LDCT findings can determine suspicion of disease and, therefore, might require workup and/or clinical management. Non-nodular pulmonary findings and nonpulmonary findings are listed among the incidental findings seen on LDCT [17]. The reporting of these findings is debated [17]. The SUMMIT study (25000 subjects; Clinical Trials.gov NCT03934866) used a pragmatic approach, aiming to report only those findings (nodules or other incidental findings) that lead to an evidencebased clinical action, reducing costs and risks [52].

Another potential LCS risk is the risk of radiation-induced cancer, which is considered acceptable but not negligible [53]. The reduction of overall radiation exposure is of great interest and can be pursued by optimized LDCT protocols as well as prolonged intervals between interval rounds (also known as low-intensity LDCT) for subjects with a low risk of LC after LDCT. The MILD trial tested two LDCT arms with either an annual or biennial algorithm and found comparable performance metrics, while achieving a $38 \%$ reduction of LDCTs [16]. This was also retrospectively tested by using Lung-RADS $\mathrm{v} 1.1_{1}$ criteria in a population selected by NLST criteria: semi-automated volumetric segmentation with LungRADS $_{\mathrm{v} 1.1}$ showed that subjects negative at baseline (category 1 and 2$)$ have a low risk of LC $(0.3 \%$ at two years, $0.6 \%$ at three years) and thus a biennial LDCT could be safe for these subjects [47]. To date, the National Health System (NHS) in England suggests low-intensity screening with biennial rounds [54], while the USPSTF guidelines still recommend annual screening [11]. Prospective trials are recruiting large populations (>25 000) to investigate the hypothesis with sufficiently powered representation (4 IN the lung run - 4ITLR) [55].

Reduction of radiation exposure could be achievable using ultra-low dose CT (ULDCT) scanning protocols, reaching sub-millisievert levels. Several studies tested the diagnostic capability of ULDCT both on phantoms and humans using different techniques like tin filtration and tube current modulation, supported by iterative reconstruction algorithms to maintain image quality $[56,57]$. Good performance in pulmonary nodule detection and measurement is reported and surely continuous technological development is warranted for the best image quality.

\section{Artificial Intelligence}

Artificial intelligence (AI) gained increasing relevance for the interpretation process of diagnostic procedures. The use of Al goes beyond nodule detection and measurement. In fact, in the near future quantitative descriptors will be able to characterize nodule behavior [58].

Several studies investigated the performance of radiomicbased quantitative analysis, but they reported different models which are hardly comparable to one another $[59,60]$.

Hawkins et al. showed that a subset of radiomics features (nodule size, attenuation, location, dimension, and texture) extracted from indeterminate nodules at baseline in the NLST popula- tion can be used to predict the occurrence of LC with an accuracy of $80 \%$ [59]. A recent study by Ardila et al. showed early results in the development of a deep learning risk prediction model outperforming six radiologists and achieving an $11 \% \mathrm{FP}$ and $5 \%$ false-negative reduction, when prior LDCT was not available [61]. Interesting results were achieved by the Lung Cancer PredictionCNN (LCP-CNN) deep learning model, which was found to outperform the Brock model with a sensitivity higher than 99\% [62]. These findings could be important to LCS implementation with the aim of improving the accuracy and efficiency of LDCT reading.

\section{Conclusion}

The secondary prevention of LC by LDCT showed a reduction of LC mortality across a variety of selection criteria, nodule management protocols, and screening strategies. Multidimensional risk models offer the opportunity for targeted selection of participants at high risk for LC. Still, engagement policies have to take into account that screening candidates might refrain from participating in such programs. Therefore, systematic analysis of society characteristics is warranted to increase screening among communities that are less likely to respond to screening invitations. A tailored approach with a personalized screening algorithm offers the potential to optimize efficiency by providing low-intensity screening rounds based on a patient's risk, including risk stratification based on LDCT and emerging circulating biomarkers. Finally, it cannot be overemphasized that primary prevention with smoking cessation remains the main action to reduce LC mortality in high-risk subjects.

\section{Conflict of Interest}

The authors declare that they have no conflict of interest.

\section{References}

[1] ECIS - European Cancer Information System From From https://ecis.jrc. ec.europa.eu, accessed on 23/09/2020 @ European Union 2020.

[2] WHO/Europe |. European tobacco use: Trends report 2019. 2019 https://www.euro.who.int/en/health-topics/disease-prevention/tobacco/ publications/2019/european-tobacco-use-trends-report-2019-2019 (accessed November 6, 2020)

[3] Field JK, Duffy SW, Baldwin DR et al. The UK lung cancer screening trial: A pilot randomised controlled trial of low-dose computed tomography screening for the early detection of lung cancer. Health Technol Assess (Rockv) 2016; 20: doi:10.3310/hta20400

[4] Infante M, Cavuto S, Lutman FR et al. Long-Term Follow-up Results of the DANTE Trial, a Randomized Study of Lung Cancer Screening with Spiral Computed Tomography. Am J Respir Crit Care Med 2015; 191: 11661175. https://doi.org/10.1164/rccm.201408-1475OC

[5] Pastorino U, Silva M, Sestini S et al. Prolonged lung cancer screening reduced 10-year mortality in the MILD trial: new confirmation of lung cancer screening efficacy. Ann Oncol 2019; 30: 1162-1169. https://doi.org/10.1093/annonc/mdz117

[6] Wille MMW, Dirksen A, Ashraf H et al. Results of the Randomized Danish Lung Cancer Screening Trial with Focus on High-Risk Profiling. Am J Respir Crit Care Med 2016; 193: 542-551. https://doi.org/10.1164/ rccm.201505-10400C 
[7] Paci E, Puliti D, Lopes Pegna A et al. Mortality, survival and incidence rates in the ITALUNG randomised lung cancer screening trial. Thorax 2017; 72: 825-831. https://doi.org/10.1136/thoraxjnl-2016-209825

[8] Aberle DR, Adams AM, Berg CD et al. Reduced lung-cancer mortality with low-dose computed tomographic screening. N Engl J Med 2011; 365: 395-409. https://doi.org/10.1056/NEJMoa1102873

[9] De Koning HJ, Van Der Aalst CM, De Jong PA et al. Reduced lung-cancer mortality with volume CT screening in a randomized trial. N Engl J Med 2020; 382: 503-513. https://doi.org/10.1056/NEJMoa1911793

[10] Becker N, Motsch E, Trotter A et al. Lung cancer mortality reduction by LDCT screening - Results from the randomized German LUSI trial. Int J Cancer 2020; 146: 1503-1513. https://doi.org/10.1002/ijc.32486

[11] Moyer VA. Screening for lung cancer: U. S. preventive services task force recommendation statement. Ann Intern Med 2014; 160: 330-338. https://doi.org/10.7326/m13-2771

[12] Scholten ET, Horeweg N, de Koning HJ et al. Computed tomographic characteristics of interval and post screen carcinomas in lung cancer screening. Eur Radiol 2015; 25: 81-88. https://doi.org/10.1007/ s00330-014-3394-4

[13] Silva M, Prokop M, Jacobs C et al. Long-Term Active Surveillance of Screening Detected Subsolid Nodules is a Safe Strategy to Reduce Overtreatment. J Thorac Oncol 2018; 13: 1454-1463. https://doi.org/ 10.1016/j.jtho.2018.06.013

[14] National Lung Screening Trial Research Team T. Lung Cancer Incidence and Mortality with Extended Follow-up in the National Lung Screening Trial The National Lung Screening Trial Research Team* 2019. https:// doi.org/10.1016/j.jtho.2019.05.044

[15] Yousaf-Khan U, Van Der Aalst C, De Jong PA et al. Final screening round of the NELSON lung cancer screening trial: The effect of a 2.5 -year screening interval. Thorax 2017; 72: 48-56. https://doi.org/10.1136/ thoraxjnl-2016-208655

[16] Pastorino U, Sverzellati N, Sestini S et al. Ten-year results of the Multicentric Italian Lung Detection trial demonstrate the safety and efficacy of biennial lung cancer screening. Eur J Cancer 2019; 118: 142-148. https://doi.org/10.1016/j.ejca.2019.06.009

[17] Kauczor HU, Baird AM, Blum TG et al. ESR/ERS statement paper on lung cancer screening. Eur Radiol 2020; 30: 3277-3294. https://doi.org/ $10.1007 / \mathrm{s} 00330-020-06727-7$

[18] Criss SD, Cao P, Bastani M et al. Cost-effectiveness analysis of lung cancer screening in the United States. Ann Intern Med 2019; 171: 796-804. https://doi.org/10.7326/M19-0322

[19] Maciosek MV, Coffield AB, Edwards NM et al. Priorities Among Effective Clinical Preventive Services. Results of a Systematic Review and Analysis. Am J Prev Med 2006; 31: 52-61. https://doi.org/10.1016/ j.amepre.2006.03.012

[20] Pastorino U, Boffi R, Marchiano A et al. Stopping smoking reduces mortality in low-dose computed tomography screening participants. J Thorac Oncol 2016; 11: 693-699. https://doi.org/10.1016/j.jtho.2016.02.011

[21] Sverzellati N, Cademartiri F, Bravi F et al. Relationship and prognostic value of modified coronary artery calcium score, FEV 1, and emphysema in lung cancer screening population: The MILD trial. Radiology 2012; 262: 460-467. https://doi.org/10.1148/radiol.11110364

[22] Chiles C, Duan F, Gladish GW et al. Association of coronary artery calcification and mortality in the national lung screening trial: A comparison of three scoring methods. Radiology 2015; 276: 82-90. https://doi.org/ $10.1148 /$ radiol.15142062

[23] Tammemägi MC, Katki HA, Hocking WG et al. Selection criteria for lungcancer screening. N Engl ] Med 2013; 368: 728-736. https:/doi.org/ 10.1056/NEJMoa1211776
[24] Tammemagi MC, Schmidt H, Martel S et al. Participant selection for lung cancer screening by risk modelling (the Pan-Canadian Early Detection of Lung Cancer [PanCan] study): a single-arm, prospective study. Lancet Oncol 2017; 18: 1523-1531. https://doi.org/10.1016/ S1470-2045(17)30597-1

[25] Hüsing A, Kaaks R. Risk prediction models versus simplified selection criteria to determine eligibility for lung cancer screening: an analysis of German federal-wide survey and incidence data. Eur J Epidemiol 2020; 35: 899-912. https://doi.org/10.1007/s10654-020-00657-w

[26] Field JK, Vulkan D, Davies MPA et al. Liverpool lung project lung cancer risk stratification model: Calibration and prospective validation. Thorax 2020. doi:10.1136/thoraxjnl-2020-215158

[27] McRonald FE, Yadegarfar G, Baldwin DR et al. The UK Lung Screen (UKLS): Demographic profile of first 88897 approaches provides recommendations for population screening. Cancer Prev Res 2014; 7: 362371. https://doi.org/10.1158/1940-6207.CAPR-13-0206

[28] Patricia Rivera M, Aldrich MC, Henderson LM et al. Addressing disparities in lung cancer screening eligibility and healthcare access: An official American thoracic society statement. Am J Respir Crit Care Med 2020; 202: E95-E112. https://doi.org/10.1164/rccm.202008-3053ST

[29] Fedewa SA, Kazerooni MSEA, Studts JL et al. State Variation in Low-Dose CT Scanning for Lung Cancer Screening in the United States. J Natl Cancer Inst 2020. doi:10.1093/jnci/djaa170/5970481

[30] Guo L, Chen Q, Shen Y et al. Evaluation of a Low-Dose Computed Tomography Lung Cancer Screening Program in Henan, China. 2020; 3: 1-11 https://doi.org/10.1001/jamanetworkopen.2020.19039

[31] Crosbie PA, Balata H, Evison $\mathrm{M}$ et al. Implementing lung cancer screening: Baseline results from a community-based "Lung Health Check" pilot in deprived areas of Manchester. Thorax 2019; 74: 405-409. https://doi.org/10.1136/thoraxjnl-2017-211377

[32] Bartlett EC, Kemp SV, Ridge CA et al. Baseline Results of the West London lung cancer screening pilot study - Impact of mobile scanners and dual risk model utilisation. Lung Cancer 2020; 148: 12-19. https://doi.org/10.1016/j.lungcan.2020.07.027

[33] Pastorino U, Sestini S. Plasma microRNA Profiling as first line screening test for lung cancer detection: a prospective study (bioMILD) 2014.

[34] Gaga M, Chorostowska-Wynimko J, Horváth I et al. Validation of Lung EpiCheck ${ }^{\circledR}$, a novel methylation-based blood assay, for the detection of lung cancer in European and Chinese high-risk individuals. Eur Respir J 2021; 57: 2002682. doi:10.1183/13993003.02682-2020. PMID: 33122336;

[35] Sullivan FM, Mair FS, Anderson W et al. Earlier diagnosis of lung cancer in a randomised trial of an autoantibody blood test followed by imaging. Eur Respir ] 2020. doi:10.1183/13993003.00670-2020

[36] Devaraj A. Missed cancers in lung cancer screening - more than meets the eye. Eur Radiol 2015; 25: 89-91. https://doi.org/10.1007/ s00330-014-3395-3

[37] Huang P, Park S, Yan R et al. Added value of computer-aided CT image features for early lung cancer diagnosis with small pulmonary nodules: A matched case-control study. Radiology 2018; 286: 286-295. https://doi.org/10.1148/radiol.2017162725

[38] Matsumoto S, Ohno Y, Aoki T et al. Computer-aided detection of lung nodules on multidetector $\mathrm{CT}$ in concurrent-reader and second-reader modes: A comparative study. Eur J Radiol 2013; 82: 1332-1337. https://doi.org/10.1016/j.ejrad.2013.02.005

[39] Christe A, Leidolt L, Huber A et al. Lung cancer screening with CT: Evaluation of radiologists anddifferent computer assisted detection software (CAD) as first andsecond readers for lung nodule detection at different dose levels. Eur J Radiol 2013; 82: doi:10.1016/ j.ejrad.2013.08.026 
[40] Silva M, Schaefer-Prokop CM, Jacobs C et al. Detection of Subsolid Nodules in Lung Cancer Screening Complementary Sensitivity of Visual Reading and Computer-Aided Diagnosis. Investig Radiol 2004. doi:10.1097/RLI.0000000000000464

[41] Devaraj A, Van Ginneken B, Nair A et al. Use of volumetry for Lung nodule management: Theory and Practice 1 STATE OF THE ART: Volumetry for Lung Nodule Management Devaraj et al. Radiol n Radiol 2017; 284: doi:10.1148/radiol.2017151022

[42] Hwang EJ, Goo JM, Kim HY et al. Variability in interpretation of low-dose chest CT using computerized assessment in a nationwide lung cancer screening program: comparison of prospective reading at individual institutions and retrospective central reading. Eur Radiol 2020. doi:10.1007/s00330-020-07424-1

[43] British Thoracic Society Pulmonary Nodule Guideline Development Group. Pulmonary Nodules | British Thoracic Society | Better lung health for all. Thorax 2015; 70: 1188. doi:10.1136/thoraxjnl-2015207168corr1

[44] Oudkerk M, Liu SY, Heuvelmans MA et al. Lung cancer LDCT screening and mortality reduction - evidence, pitfalls and future perspectives. Nat Rev Clin Oncol 2020. doi:10.1038/s41571-020-00432-6

[45] Pinsky PF, Gierada DS, Black W et al. Performance of lung-RADS in the national lung screening trial: A retrospective assessment. Ann Intern Med 2015; 162: 485-491. https://doi.org/10.7326/M14-2086

[46] Gierada DS, Rydzak CE, Zei M et al. Improved Interobserver Agreement on Lung-RADS Classification of Solid Nodules Using Semiautomated CT Volumetry. Radiology 2020. doi:10.1148/radiol.2020200302

[47] Silva M, Milanese G, Sestini S et al. Lung cancer screening by nodule volume in Lung-RADS v1.1: negative baseline CT yields potential for increased screening interval. Eur Radiol 2020. doi:10.1007/ s00330-020-07275-w

[48] Zhu Y, Yip R, You N et al. Management of Nodules Attached to the Costal Pleura at Low-Dose CT Screening for Lung Cancer. Radiology 2020. doi:10.1148/radiol.2020202388

[49] Hammer MM, Byrne SC, Kong CY. Factors Influencing the False Positive Rate in CT Lung Cancer Screening. Acad Radiol 2020: 1-5 doi:10.1016/j.acra.2020.07.040

[50] Welch HG, Black WC. Overdiagnosis in cancer. J Natl Cancer Inst 2010; 102: 605-613. https://doi.org/10.1093/jnci/djq099

[51] González Maldonado S, Motsch E, Trotter A et al. Overdiagnosis in lung cancer screening: Estimates from the German Lung Cancer Screening Intervention Trial. Int J Cancer 2020. doi:10.1002/ijc.33295
[52] Horst C, Dickson JL, Tisi S et al. Delivering low-dose CT screening for lung cancer: A pragmatic approach. Thorax 2020; 75: 831-832. https://doi.org/10.1136/thoraxjnl-2020-215131

[53] Rampinelli C, De Marco P, Origgi D et al. Exposure to low dose computed tomography for lung cancer screening and risk of cancer: Secondary analysis of trial data and risk-benefit analysis. BMJ 2017; 356: 347 https://doi.org/10.1136/bmj.j347

[54] NHS England - National Cancer Programme. Targeted Screening for Lung Cancer with Low Radiation Dose Computed Tomography 2019; 1-30.

[55] 4-IN THE LUNG RUN: towards INdividually tailored INvitations, screening INtervals, and INtegrated co-morbidity reducing strategies in lung cancer screening | 4-IN THE LUNG RUN Project | H2020 | CORDIS | European Commission n.d. https://cordis.europa.eu/project/id/848294 (accessed November 6, 2020)

[56] Milanese G, Silva M, Frauenfelder T et al. Comparison of ultra-low dose chest CT scanning protocols for the detection of pulmonary nodules: a phantom study. Tumori 2019; 105: 394-403. https://doi.org/10.1177/ 0300891619847271

[57] Ye K, Zhu Q, Li M et al. A feasibility study of pulmonary nodule detection by ultralow-dose CT with adaptive statistical iterative reconstruction-V technique. Eur J Radiol 2019; 119: doi:10.1016/j.ejrad.2019.108652

[58] Ciompi F, Chung K, Van Riel S] et al. Towards automatic pulmonary nodule management in lung cancer screening with deep learning. Sci Rep 2017; 7: doi:10.1038/srep46479

[59] Hawkins S, Wang H, Liu Y et al. Predicting Malignant Nodules from Screening CT Scans. J Thorac Oncol 2016; 11: 2120-2128. https://doi. org/10.1016/j.jtho.2016.07.002

[60] Xu Y, Lu L, Lin-ning E et al. Application of Radiomics in Predicting the Malignancy of Pulmonary Nodules in Different Sizes. Am J Roentgenol 2019; 213: 1213-1220. https://doi.org/10.2214/AJR.19.21490

[61] Ardila D, Kiraly AP, Bharadwaj S et al. End-to-end lung cancer screening with three-dimensional deep learning on low-dose chest computed tomography. Nat Med 2019; 25: 954-961. https://doi.org/10.1038/ s41591-019-0447-x

[62] Baldwin DR, Gustafson J, Pickup L et al. External validation of a convolutional neural network artificial intelligence tool to predict malignancy in pulmonary nodules. Thorax 2020; 75: 306-312. https://doi.org/ 10.1136/thoraxjnl-2019-214104 